\title{
Reação de híbridos de citros à inoculação com Alternaria alternata
}

\author{
Thais Helena Villa Michielin ${ }^{1}$, Mariângela Cristofani-Yaly ${ }^{1,2}$, Kelly Aparecida Fernandes de Campos ${ }^{1}$, Evandro \\ Henrique Schinor ${ }^{3}$, Fernando Alves de Azevedo ${ }^{2}$ e Marinês Bastianel ${ }^{2}$
}

${ }^{1}$ Programa de Pós-Graduação em Produção Vegetal e Bioprocessos Associados, Universidade Federal de São Carlos, Araras, SP. ${ }^{2}$ Centro APTA Citros Sylvio Moreira, Instituto Agronômico, Cordeirópolis, SP, CP 04. CEP 13490 970. ${ }^{3}$ Centro de Ciências Agrárias, Universidade Federal de São Carlos, Araras, SP, CP 153, CEP 13600-970.

Autor para correspondência:Marinês Bastianel (mbastianel@centrodecitricultura.br)

Data de chegada: 19/05/2016. Aceito para publicação em: 29/06/2016.

\section{RESUMO}

Michielin, T.H.V.; Cristofani-Yaly, M.; Campos, K.A.F.; Schinor, E.H.; Azevedo, F.A.; Bastianel, M. Reação de híbridos de citros à inoculação com Alternaria alternata. Summa Phytopathologica, v.42, n.4, p.313-320, 2016.

A mancha marrom de alternária (MMA), causada por Alternaria alternata, que produz uma toxina específica ao hospedeiro (Host Specific Toxin - HST) é uma doença de grande importância nos pomares de tangerinas no mundo. A doença afeta tangerinas, alguns de seus híbridos interespecíficos e pomelos, sendo que no Brasil, as principais variedades plantadas, a tangerina Ponkan e o tangor Murcott, são altamente suscetíveis ao fungo, que também é saprofítico alternativo, se reproduz nos pomares, sendo seus esporos facilmente disseminados pelo vento. Para esse trabalho, foram selecionados híbridos de citros, obtidos por cruzamentos dirigidos, por apresentarem características agronômicas que os tornam potenciais novas variedades de laranjas e tangerinas, tanto para a citricultura industrial, quanto de mesa. Esses híbridos foram avaliados quanto à resposta à MMA por meio da inoculação com $A$. alternata in vitro e in vivo, uma etapa imprescindível para a liberação de novas variedades. Foram selecionados mais de trinta genótipos resistentes ou que apresentaram poucos sintomas da doença. A seleção de variedades resistentes à doença é de grande importância econômica, pois além de diminuir os custos de produção, aumentados sobremaneira com a utilização do controle químico, contribui para a diminuição de inóculo no campo.

Palavras-chave: Laranja, tangerina, doenças dos citros, fungo.

\section{ABSTRACT}

Michielin, T.H.V.; Cristofani-Yaly, M.; Campos, K.A.F.; Schinor, E.H.; Azevedo, F.A.; Bastianel, M. Reaction of citrus hybrids to inoculation with Alternaria alternata. Summa Phytopathologica, v.42, n.4, p.313-320, 2016.

Alternaria brown spot (ABS), caused by Alternaria alternata, which produces a host-specific toxin (HST), is a very important disease in mandarin orchards worldwide. This disease affects mandarin, their hybrids and grapefruits. The main varieties cultivated in Brazil, Ponkan mandarin and Murcott tangor, are highly susceptible to the fungus, which is also an alternative saprophyte that reproduces in the orchards and has its spores easily spread by the wind. For this study, citrus hybrids obtained from directed crossing were selected for their agronomic traits, which make them potential new varieties of sweet orange and mandarins both for industrial citriculture and for fresh fruit market. These hybrids were evaluated for their response to ABS by means of A. alternata inoculation in vitro and in vivo, an indispensible step for the release of new varieties. More than 30 genotypes that were resistant or had few symptoms of the disease were selected. Selection of varieties resistant to the disease is of great economic importance, since it reduces the production costs, rather increased due to chemical control, and also contributes to the inoculum decrease in the field.

Keywords: Sweet orange, orange, citrus diseases, fungus

A citricultura é uma importante atividade econômica no Brasil, e uma das principais atividades do agronegócio do estado de São Paulo, maior polo produtor de citros do país. Nos pomares brasileiros, há a predominância da laranja doce (Citrus sinensis Osbeck), sendo que o país, maior produtor mundial, produziu 17,54 milhões de toneladas de frutos, em 2013 (13). A produção de laranjas é destinada principalmente às indústrias de suco, sendo que o Brasil, através da produção de São Paulo, é o maior exportador mundial de suco de laranja industrializado (13). As tangerinas, terceiro grupo em importância em citros nos pomares brasileiros, englobam várias espécies e híbridos e são produzidas basicamente para o mercado de frutas de mesa. O país ocupa o quarto lugar no ranking mundial de produção de tangerinas, com 955 mil toneladas (13), distribuídas em 49,8 mil hectares, localizados principalmente, nas regiões Sudeste e Sul (17).

Poucas variedades compõem a citricultura brasileira tanto para a indústria quanto para o mercado de frutas frescas, o que torna a citricultura vulnerável aos problemas fitossanitários. A mancha marrom de alternaria (MMA) é causada pelo fungo Alternaria alternata (28, 34,35 ); que produz uma toxina seletiva ao hospedeiro (HST), cuja suscetibilidade está restrita às tangerinas, pomelos (C. paradisi Macf), tangores (híbridos de laranja x tangerina) e alguns de seus híbridos (3, $6,23,26,33,36)$. Os sintomas causados pela toxina caracterizam-se por lesões necrosadas em ramos, frutos, tecidos verdes imaturos ou em fase de crescimento, podendo ocorrer um desfolhamento intenso durante os períodos de maior infecção, em vista da necrose das folhas e uma redução na produção pela queda de frutos $(3,32,34,35)$.

Presente nos pomares brasileiros desde $2001(26,31)$, a doença é endêmica nas principais regiões produtoras, sendo necessário um elevado número de aplicações de fungicidas para o seu controle, desestimulando o plantio de variedades suscetíveis em novas áreas $(2,3,32)$, o que faz com que a seleção e plantio de novas variedades resistentes sejam de grande importância e interesse para o 
desenvolvimento da citricultura comercial.

Em trabalhos prévios, centenas de híbridos foram obtidos por cruzamentos dirigidos entre diferentes genitores no Programa de Melhoramento de Citros do Centro APTA Citros Sylvio Moreira/ Instituto Agronômico (Cordeirópólis, SP). Progênies obtidas de diferentes cruzamentos foram avaliadas para diferentes características agronômicas $(4,9,22)$ e novos materiais foram selecionados por apresentarem boas características de fruto e potencial comercial, tanto para indústria de suco, como para o mercado de frutas frescas.

Estes híbridos foram pré-selecionados nas diferentes progênies estabelecidas em diferentes locais de plantio no estado de São Paulo, por apresentarem características fenotípicas desejáveis em variedades comerciais, tais como: bom aspecto da planta, boa produção e boas características gerais de fruto como a cor da casca, cor da polpa e do suco, sabor; facilidade de descascamento, entre outras. Com base nestas avaliações os híbridos foram classificados como tipo laranja, pela forma de fruto, casca lisa e aderida; tipo tangerina, pela facilidade de descasque, casca solta e gomos facilmente separáveis; tipo mexerica, pela presença de casca fina, solta e aroma característico do grupo, e tipo Murcott, pela semelhança a este tangor, como formato achatado e casca fina e aderida.

Entretanto, por serem oriundos de cruzamentos com pelo menos um dos genitores suscetível à MMA, o conhecimento sobre a resposta a esta doença é uma etapa importante na seleção de novas variedades. Assim, foram avaliados dezenas de híbridos e seus respectivos genitores, quanto à resposta à inoculação do fungo causador da MMA, em folhas destacadas (in vitro) e em plantas jovens (in vivo) com o objetivo de selecionar variedades resistentes à doença, com potencial para ampliar o atual quadro varietal de citros.

\section{MATERIAIS E MÉTODOS}

\section{Material vegetal}

Foram avaliados 89 genótipos de citros (Tabela 1), incluindo 79 híbridos, sete genitores e três testemunhas, sendo estas as tangerinas Fremont IAC 543 (Citrus reticulata Blanco x C. clementina Hort. ex Tanaka), Clementina de Nules IAC 1742 (C. clementina), ambas resistentes à MMA e a tangerina Dancy IAC 188 (C. reticulata Blanco), suscetível à MMA, conforme descrito por Azevedo et al. (3).
Os híbridos avaliados foram pré-selecionados em função de características agronômicas em ensaios de validação, classificados por tipo/grupo de citros (laranja, tangerina, mexerica e tangor) com base nas suas características de frutos e incluíam nove híbridos de tangerina Cravo (C. reticulata Blanco) $\mathrm{x}$ laranja Pêra ( $C$. sinensis Osbeck), dois híbridos de tangelo Orlando (C. reticulata Blanco x Citrus paradisi Macf.) x laranja Pêra, dois híbridos de tangor Murcott (C. reticulata x C. sinensis) x laranja Valência (C. sinensis), 52 híbridos de tangor Murcott x laranja Pêra, oito híbridos de tangor Murcott x tangerina Ponkan (C. reticulata), cinco híbridos de mexerica do Rio (C. deliciosa Tenore) $\mathrm{x}$ laranja Pera e um híbrido de tangerina Cravo (C. reticulata) $\mathrm{x}$ laranja Valência (C. sinensis). Dentre os híbridos avaliados, incluíam 45 classificados como laranjas, 18 como tangerinas, cinco como mexericas e 11 como tangores tipo Murcott (Tabela 1).

Estes materiais estão presentes na coleção de novos híbridos do Banco Ativo de Germoplasma (BAG) do Centro APTA Citros Sylvio Moreira/IAC, no município de Cordeirópolis/SP, todos mantidos em vasos de 20 litros com substrato apropriado em estufa telada. As inoculações foram realizadas em folhas destacadas e em plantas jovens.

Para o experimento de avaliação em folhas destacadas (in vitro) o delineamento experimental foi inteiramente casualizado com três repetições, sendo cada uma composta por uma placa de Petri contendo três folhas de cada genótipo. Folhas jovens de cada genótipo (2-3 cm de comprimento), com aproximadamente 15 dias, foram coletadas, lavadas em água corrente e acondicionadas em placas de Petri, contendo uma camada de papel de filtro e uma pequena porção de algodão umedecido. As placas foram mantidas em BOD a $27^{\circ} \mathrm{C}$ com fotoperíodo de 12 horas.

Para as inoculações em planta, foram propagadas via enxertia (borbulhas) cópias de cada genótipo, em porta-enxerto limão Cravo (C. limonia Osbeck), em sacolas plásticas de 4 litros, cultivadas em substrato apropriado, e mantidas em casa de vegetação. Após seis meses da enxertia, as plantas foram podadas para estimular a brotação. Para as inoculações foram selecionadas três plantas de cada genótipo, em função da presença de folhas novas $(3-5 \mathrm{~cm})$ e acondicionadas em sala aclimatizada, com temperatura $\left(27 \pm 1^{\circ} \mathrm{C}\right)$ e umidade relativa $(85 \pm 5 \%)$ controladas, em delineamento completamente casualizado.

\section{Isolado do fungo e preparo do inóculo}

Um isolado de Alternaria alternata foi obtido a partir de lesões típicas em frutos de tangor Murcott, altamente suscetível, coletados no

Tabela 1. Relação e classificação dos híbridos selecionados em ensaios estabelecidos em diferentes regiões do estado de São Paulo que foram avaliados quanto à resposta à mancha marrom de alternaria.

\begin{tabular}{lll}
\hline $\begin{array}{l}\text { Classificação pela } \\
\text { característica de fruto }\end{array}$ & Cruzamento* & $\mathrm{N}^{\mathbf{0}}$ do híbrido \\
\hline & TC x LP & $05,10,47,62,66,69,88$ \\
& TO x LP & 06,25 \\
Laranja & TM x LV & $104 \mathrm{a}, 117 \mathrm{a}$ \\
& & $5,12,13,14,16,23,42,50,88,97,105,107,110,111,112,113,116,163,170,180,188,200,202,203 \mathrm{c}, 225,233$, \\
& TM x LP & $279,285,290,324,326,338,345,354$ \\
\hline & TC x LV & 15 \\
& TC x LP & 24,48 \\
& TM x LP & $87,175,203 i, 217,222,258,358$ \\
& TM x TP & $02,03,04,08,09,11,12,13$ \\
\hline Mexerica & MC x LP & $07,140,319,355,367$ \\
\hline Murcott & TM x LP & $33,61,124,157,246,265,281,302,321,253,353$ \\
\hline MC - mexerica do Rio; LP - laranja Pêra; LV- laranja Valência; TC- tangerina Cravo; TM - tangor Murcott; TO - tangelo Orlando; TP - tangerina Ponkan.
\end{tabular}


campo em plantio estabelecido no Centro APTA Citros Sylvio Moreira em Cordeirópolis, SP, local onde ocorre o fungo de forma endêmica. Para a obtenção do isolado foi utilizada a metodologia descrita por Peever et al. (24), com modificações (3). As lesões foram escolhidas, separadas e desinfestadas superficialmente por meio de lavagens (etanol 70\%, hipoclorito de sódio, 3\% de cloro ativo e água destilada esterilizada) e incubadas em placas de Petri contendo meio de cultura

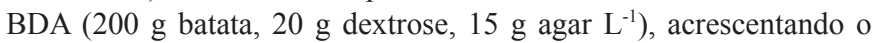
fungicida carbendazin ( $640 \mathrm{mg} \mathrm{L}^{-1}$ do i.a.) para excluir a proliferação de outros fungos oportunistas, sendo em seguida, mantidos em fotoperíodo de 12 horas, a $27^{\circ} \mathrm{C}$, por 48 horas em BOD.

Após período de incubação (48 horas), hifas características foram identificadas com o auxílio de microscópio óptico, sendo estas transferidas e incubadas nas mesmas condições do isolado inicial, durante período de cinco dias onde ocorreu a indução do crescimento micelial do fungo fitopatogênico. A obtenção do isolado do fungo, assim como os experimentos de inoculação foram conduzidos no laboratório de Melhoramento e Qualidade do Fruto (MQF) do Centro de Citricultura, em Cordeirópolis, SP.

Para a produção de uma suspensão de conídios foram transferidos discos de micélio do fungo ( $5 \mathrm{~mm}$ de diâmetro) de culturas de cinco dias de idade, para placas de Petri contendo meio de esporulação (30 $\mathrm{g}$ de $\mathrm{CaCO}_{3}, 20 \mathrm{~g}$ de sacarose e $20 \mathrm{~g}$ de ágar $\mathrm{L}^{-1}$ ), foram incubadas em fotoperíodo de 12 horas, por quatro dias, em BOD, a $27^{\circ} \mathrm{C}$, conforme descrito por Canihos et al. (7). Na sequência, com a ajuda de uma espátula estéril, os conídios foram retirados da superfície da placa, e ressuspendidos em água destilada esterilizada. A suspensão de conídios foi filtrada em duas camadas de gazes esterilizadas, para a remoção dos fragmentos miceliais, sendo a concentração ajustada, após várias contagens, para $1,0 \times 10^{5}$ conídios $\mathrm{mL}^{-1}$, com auxílio de hemocitômetro.

\section{Inoculação e avaliação dos sintomas de Alternaria alternata}

As inoculações nas folhas destacadas e em plantas foram realizadas, na face abaxial das folhas, com uma suspensão de esporos de $A$. alternata $\left(10^{5}\right.$ conídios $\left.\mathrm{mL}^{-1}\right)$, utilizando-se um borrifador manual (2 $\mathrm{mL}$ folha $\left.{ }^{-1}\right)$.

Para o experimento de folhas destacadas, as avaliações da doença foram realizadas após 24, 48 e 72 horas da inoculação do patógeno, de acordo com uma escala diagramática, descrita por Martelli (21), representando os níveis de sintoma em dez notas devidamente ilustradas, onde " 0 " representa folha sem sintomas, e as notas de " 1 " a "9" representam 0,$3 ; 3,5 ; 8 ; 15 ; 34 ; 61 ; 80 ; 90$ e 97 por cento de área foliar tomada por sintomas de Alternaria alternata.

No experimento em plantas jovens (in vivo), a avaliação foi realizada após 72 horas da inoculação e consistiram na média da estimativa da área lesionada ( $\%$ da folha tomada pela doença), também usando a escala diagramática de Martelli (21), de todas as folhas sintomáticas de cada planta.

Os valores de severidade foram calculados a partir dos valores equivalentes aos níveis de severidade dados pela escala diagramática. As médias foram transformadas em raiz quadrada $(\mathrm{Y}+1,0)$ e após a análise de variância realizou-se a comparação de médias pelo teste Scott Knott à 5\% de probabilidade, utilizando-se o software SISVAR 4.5 (14).

\section{RESULTADOS E DISCUSSÃO}

Sintomas típicos de MMA foram observados após 24 horas de inoculação com o fungo em folhas destacadas de alguns híbridos, genitores e testemunha suscetível (tangerina Dancy). Estes sintomas se caracterizavam por pequenas manchas de coloração marrom a preta, de tamanho variado nas folhas, que em alguns casos se expandiram nas avaliações subsequentes para grandes áreas necrosadas dos tecidos foliares, possivelmente pela ação da toxina ACT, como descrito por alguns autores $(1,20)$.

Foi observada uma grande variabilidade em resposta à inoculação de $A$. alternata entre os híbridos avaliados, tanto em folhas destacadas quanto em plantas jovens (Tabela 2). Em folhas destacadas (in vitro) a porcentagem de área foliar com sintomas variou de 0 a 34 tanto entre os híbridos quanto nos genitores, após 72 horas de inoculação. Valores menores de \% de área lesionada foram observados em resposta à inoculação do fungo nas plantas (in vivo), sendo a variação observada de 0 a $19,5 \%$ entre os híbridos e de 0 a 4,5\% entre os genitores.

A tangerina Dancy, usada como testemunha suscetível, apresentou maior severidade dos sintomas, tanto em folhas destacadas $(97 \%)$ quanto em planta (44,3\%). Dentre os genitores o tangelo Orlando, a tangerina Ponkan e o tangor Murcott foram suscetíveis, exibindo respectivamente, $34,21,3$ e $12,7 \%$ de área foliar com sintomas em folhas destacadas e 4,5, 1,7 e 3,8\% em plantas. Estudos anteriores demonstraram a alta suscetibilidade destes materiais a $\operatorname{MMA}(3,18,25$, 29). Já as laranjas Pêra e Valência, tangerina Cravo, mexerica do Rio, Clementina Nules e tangerina Fremont, estas duas últimas utilizadas como testemunhas resistentes, não exibiram sintomas da doença. De fato, estas variedades têm sido relatadas como resistentes $(3,5,10)$.

Embora não sejam encontrados relatos de MMA afetando naturalmente pomares de laranjas doces, alguns trabalhos utilizando diferentes métodos de inoculação mostram diferenças nas respostas à MMA entre variedades de C. sinensis. Elena (12) relata que as variedades Lane Late, Navel Late, Oval Poros, Olinda, Navel Athos são resistentes, enquanto Karvan et al. (18), com base em inoculações em folhas destacadas, relataram três variedades cultivadas no Iran (Thomson, Local e Lime) como moderadamente suscetíveis.

Soleil e Kimchi (29), também observaram a presença de sintomas em folhas destacadas das laranjas doces Shamouti, Washington Navel e Valência, embora relatassem que as mesmas são assintomáticas em campo na Florida, mesmo quando plantadas próximas a tangelo Minneola, altamente afetado pela doença. Já Gardner et al. (15), que confirmaram a suscetibilidade de tangerinas e pomelos na Florida, relataram resultados inconclusivos em laranja doce. Quando os autores inocularam folhas de laranja Valência eles observaram apenas lesões imediatas, típicas de reação de hipersensibilidade no momento da inoculação. Estas diferenças em resposta à inoculação artificial de A. alternata em laranja doce poderia estar relacionada ao isolado do fungo, ou características fisiológicas das folhas. Neste trabalho não foi observado nenhum tipo de lesão em folhas destacadas ou em plantas das variedades de laranjas estudadas, comprovando a sua resistência ao isolado de $A$. alternata.

Dos híbridos avaliados em folhas destacadas, após 72 horas da inoculação, 31 não apresentaram sintomas da doença, 23 apresentaram poucos sintomas (\% área lesionada menor que 8 ). Os demais híbridos apresentaram diferentes níveis de suscetibilidade. Por outro lado, nas inoculações em plantas, um maior número de genótipos, 40 híbridos, mostrou-se resistente, não exibindo nenhum sintoma da doença (Tabela 2). Diferenças na severidade em inoculações em folhas destacadas e plantas são relatadas por outros autores $(3,27,29)$ e podem estar relacionadas pelas alterações físiológicas e perda da capacidade de resposta de resistência em folhas destacadas $(3,8)$. Mesmo com algumas diferenças, a correlação existente entre os dois métodos de inoculação (in vitro $\mathrm{x}$ in vivo) utilizados nesse trabalho foi alta $\left(\mathrm{R}^{2}: 0,70\right)$, evidenciando que ambos podem ser utilizados para avaliar a resposta a Alternaria 
Tabela 2. Severidade da mancha marrom de alternaria em híbridos e seus respectivos genitores em três tempos de avaliação in vitro (24, 48 e 72 horas após inoculação) e avaliação in vivo. Testemunhas: tangerinas Dancy (suscetível), Fremont e Clementina de Nules (resistentes).

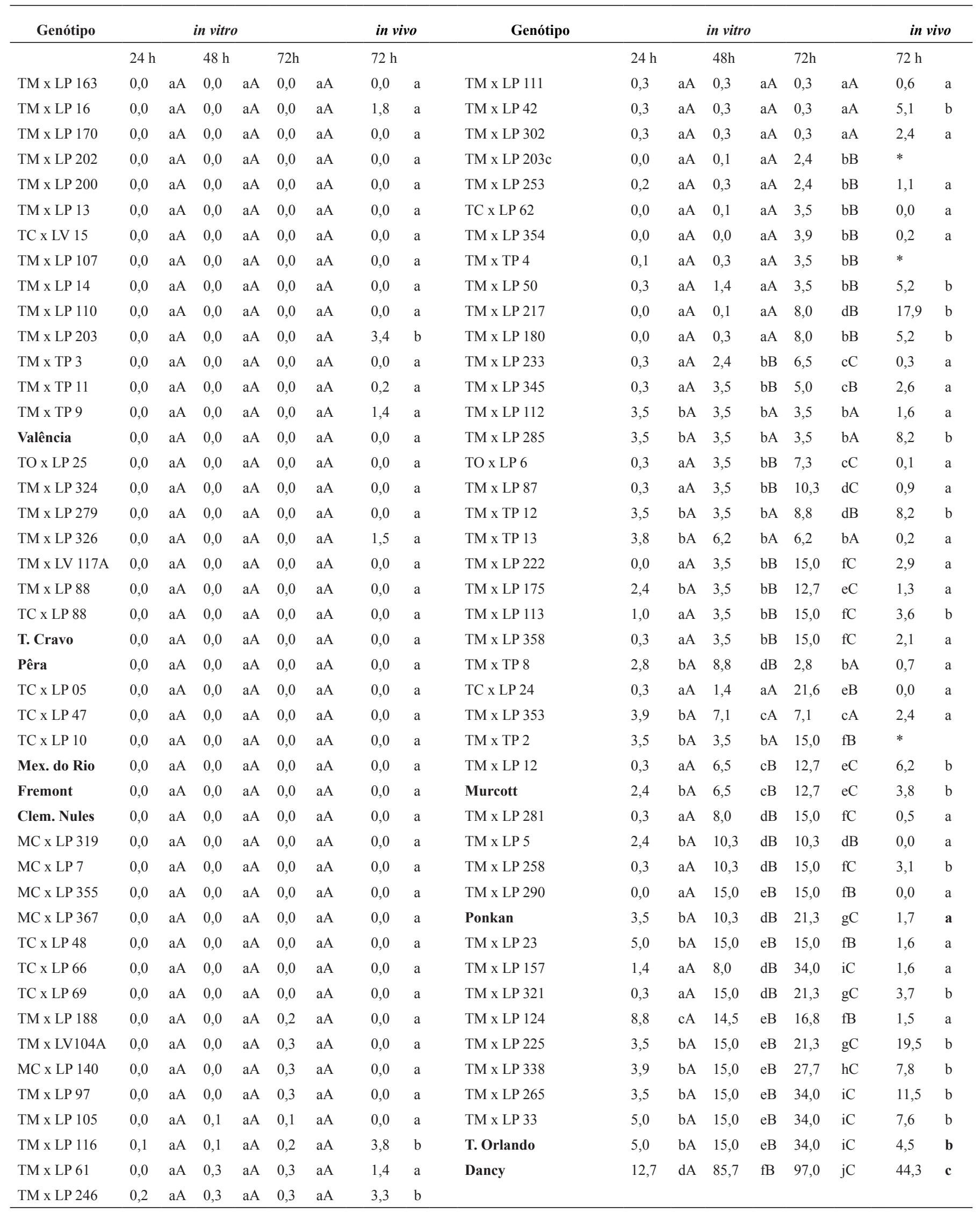

Médias seguidas de mesma letra na coluna (minúscula) e na linha (maiúscula), não diferem entre si pelo teste Scott-Knott (p>0,05). 
alternata em citros. Souza et al. (30), avaliando diferentes métodos de inoculação em genótipos do Banco de Germoplasma da Estação Experimental de Citros Bebedouro (Bebedouro, SP), encontrou relação entre nível de suscetibilidade em folhas jovens destacadas, infecção natural de folhas e frutos, e infecção artificial por inoculação em frutos.

Em geral, foi observado um aumento na severidade entre os tempos de avaliação, sendo que os valores médios de porcentagem da área sintomática variaram de 0,1 a 12,7 após 24 horas da inoculação com o fungo, de 0,1 a 85,66 após 48 horas, com oito novos híbridos apresentando sintomas, e de 0,1 a 97 no final das avaliações ( 72 horas), quando outros cinco híbridos foram sintomáticos (Tabela 2).

Quando se avalia a resposta à inoculação com $A$. alternata entre as diferentes progênies, observa-se que a maioria dos híbridos obtidos entre os genitores tangerina Cravo e laranja Pêra (TC x LP), ambos resistentes, não mostrou sintomas, sendo que apenas dois deles (TC x LP 24 e 62) apresentaram baixa porcentagem de área com lesões, somente em folhas destacadas. O mesmo foi observado nos híbridos obtidos entre mexerica Rio e laranja Pêra (MC x LP), tendo entre estes apenas um híbrido com poucos sintomas e somente após 72 horas de inoculação em folhas destacadas. Já nos híbridos de Murcott x Pera, 16 foram assintomáticos, quando inoculados em plantas, sendo que os demais mostraram diferentes níveis de suscetibilidade. $\mathrm{O}$ híbrido de Cravo x Valência (TC x LV 15) foi resistente e os híbridos de Murcott x Valência (TM x LV 104a e 117a) foram assintomáticos ou apresentaram baixa severidade dos sintomas (Tabela 2). Já os dois híbridos de Orlando x Pêra foram distintos sendo um resistente (TO x LP 25) e outro suscetível (TO x LP 06).

Alguns trabalhos sugeriram que o padrão de herança genética para a suscetibilidade em citros para a mancha marrom de alternaria seria monogênica e dominante $(10,11,16)$, sendo o alelo 'A' dominante para

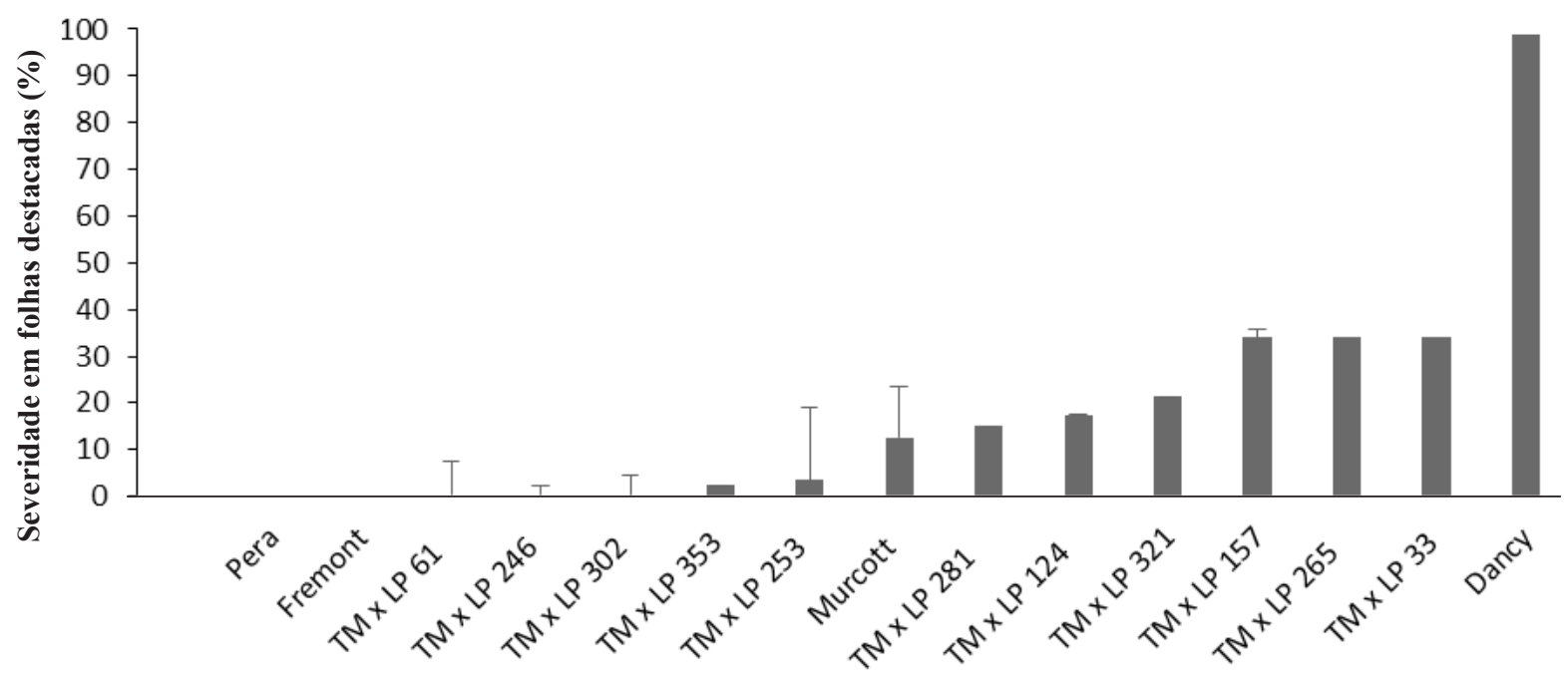

Genótipo

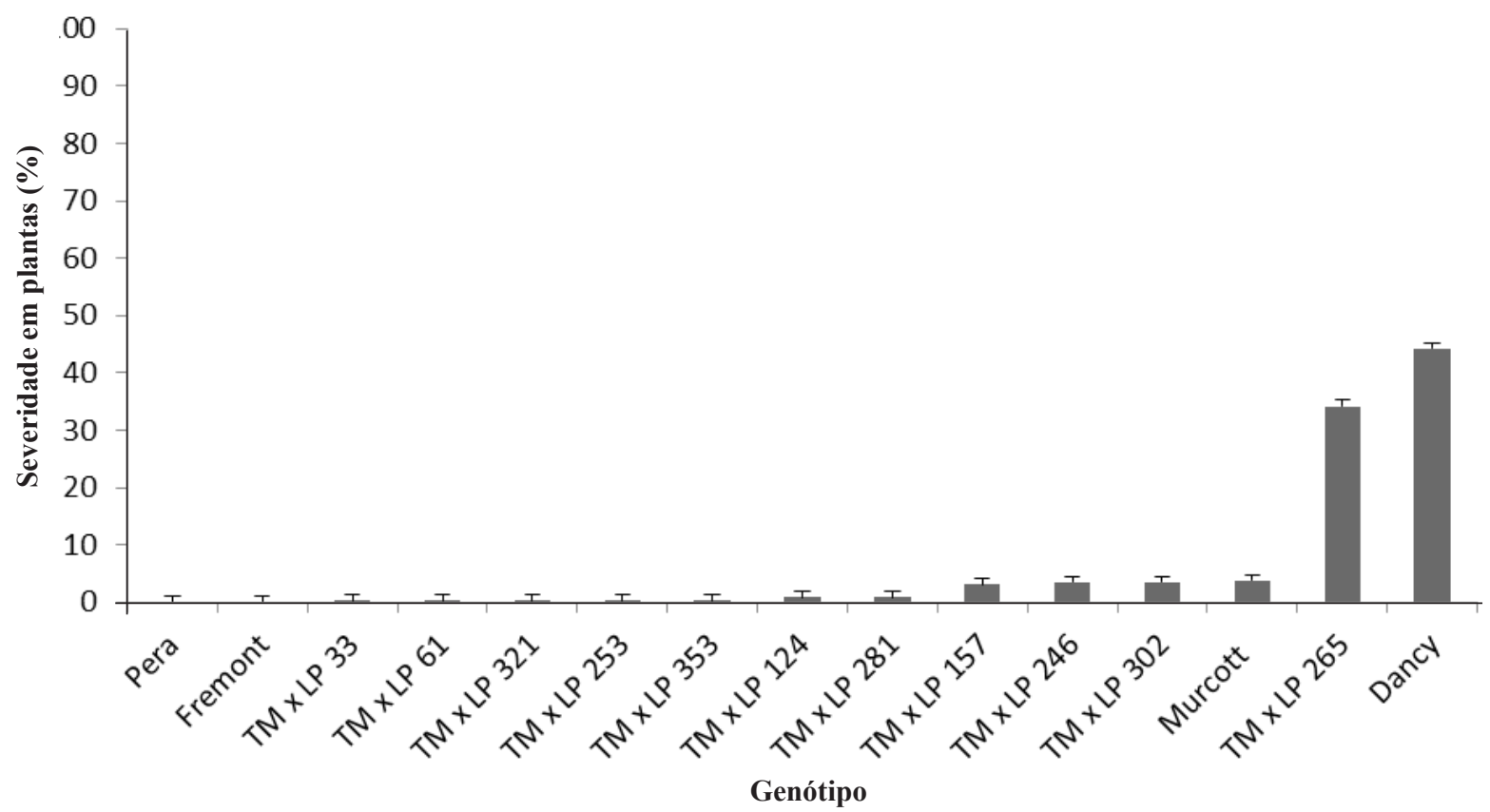

Figura 1. Severidade da doença (\%) em folhas destacadas (in vitro) e em plantas (in vivo), após 72 horas de avaliação, dos híbridos pertencentes ao grupo Murcott, genitores e testemunha resistente (Fremont) e suscetível (Dancy). 
suscetibilidade e 'a' recessivo para a resistência à doença. Com base no que foi proposto por estes autores, a laranja doce teria o genótipo 'aa' e o tangor Murcott 'Aa'. Assim, na progênie obtida entre estes dois genótipos seria esperada uma segregação mendeliana de 1:1 (resistentes:suscetíveis).

Dentre os 52 híbridos de Murcott x Pêra, foi observado após 72 horas de inoculação com o fungo em folhas destacadas, 14 híbridos assintomáticos e, portanto, resistentes a A. alternata, nove híbridos moderadamente suscetíveis, apresentando uma baixa porcentagem de área com lesões (área de lesão menor que 2) e 29 suscetíveis (área de lesão maior que 7,1). Resultado similar foi observado nas avaliações em plantas, sendo 15 assintomáticos, 19 com poucos sintomas e 17 com diferentes níveis de sintomas. Assim, os resultados mensurados com base na inoculação com o fungo, sugerem desvios da segregação mendeliana na progênie, sendo de 23:29 (in vitro) ou 34:17 (in vivo), dependendo do método de inoculação, folhas destacadas ou plantas.

Poucos estudos têm sido conduzidos para avaliar a herança genética da doença nos citros e, até o momento, se desconhece algum trabalho desta natureza envolvendo populações obtidas entre tangerinas e laranjas. Sabe-se também que a toxina ACT, produzida por A. alternata é específica para uma determinada gama de hospedeiros $(19,24)$, sendo algumas tangerinas e seus híbridos suscetíveis. Por outro lado, a observação de sintomas em algumas laranjas doces quando inoculadas in vitro $(12,18,29)$ sugerem que outros fatores ou outros genes podem estar envolvidos na interação $A$. alternata x citros.

Híbridos resistentes à inoculação com A. alternata foram encontrados dentro de todos os grupos horticulturais (mexericas, tangerinas, laranjas), exceto no grupo de tangores (Tabela 2), tanto em folhas destacadas, quanto em plantas, sendo portanto, o grupo com maior severidade da doença (Figura 1). Vale lembrar que os frutos de tangor Murcott são muito apreciados pelo consumidor brasileiro e são excelentes para o mercado interno e externo de frutas frescas, entretanto, sua área de plantio no estado de São Paulo tem sido consideravelmente diminuída em função da sua alta suscetibilidade a mancha marrom de

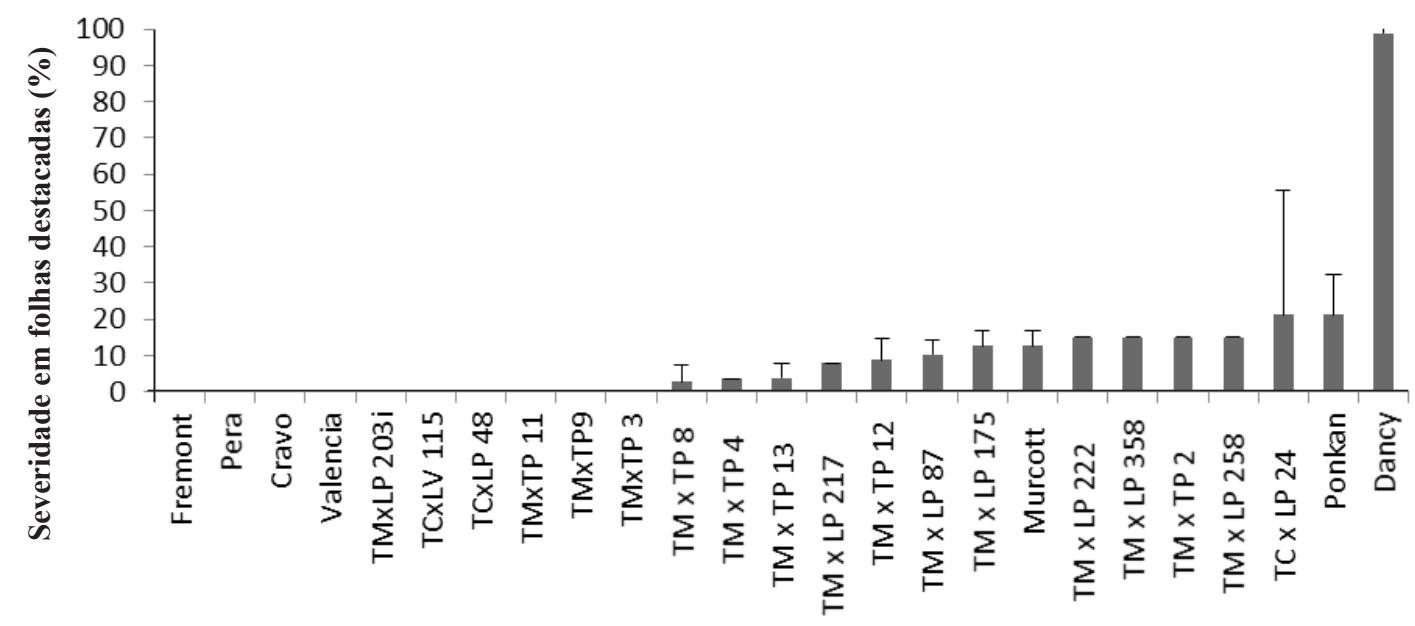

Genótipo

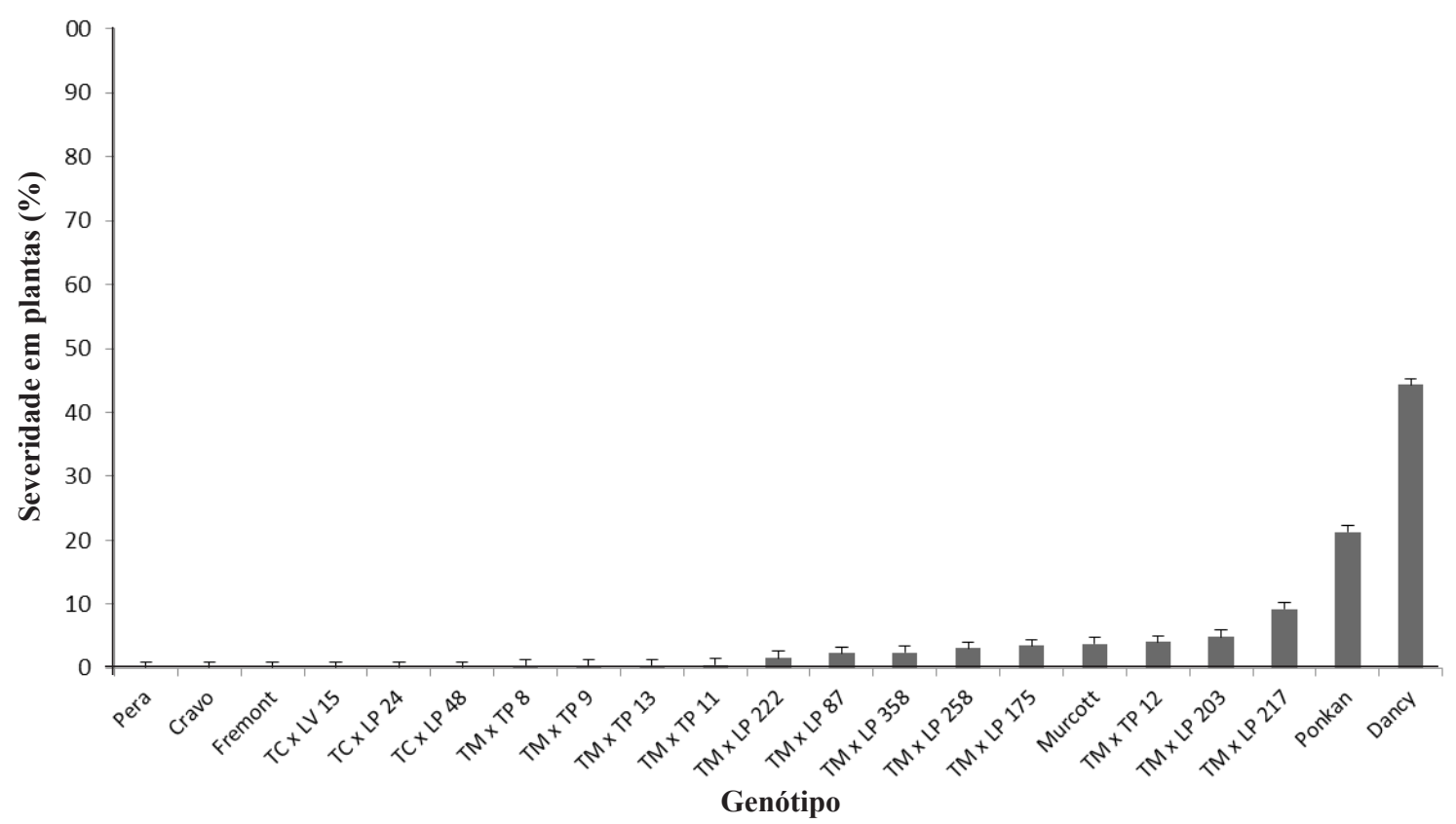

Figura 2. Severidade da doença (\%) em folhas destacadas (in vitro) e em plantas (in vivo), após 72 horas de avaliação, dos híbridos pertencentes ao grupo tangerina, genitores e testemunha resistente (Fremont) e suscetível (Dancy). 

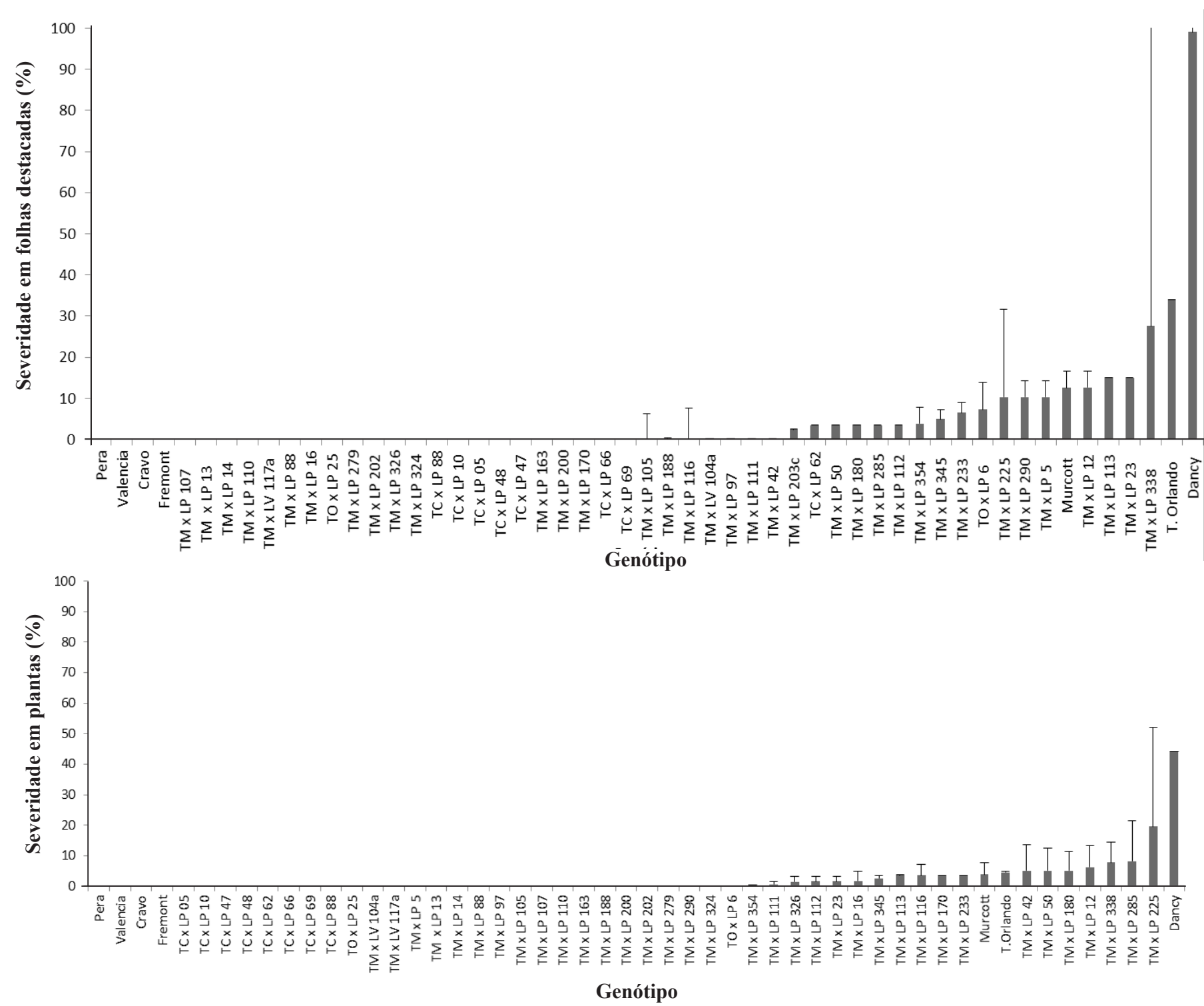

Figura 3. Severidade da doença (\%) em folhas destacadas (in vitro) e em plantas (in vivo), após 72 horas de avaliação, dos híbridos pertencentes ao grupo laranja, genitores e testemunha resistente (Fremont) e suscetível (Dancy).

alternaria $(2,23)$. Apesar de os híbridos selecionados no grupo 'Murcott' terem apresentado sintomas, quando comparados com os outros grupos, cinco deles (TM x LP 61, 246, 253, 302 e 353) apresentaram níveis de severidade menores que a Murcott, tanto quando inoculados in vitro quanto in vivo (Figura 1), após 72 horas de avaliação. Provavelmente estes materiais são resistentes no campo ou pouco suscetíveis e podem se constituir em materiais interessantes para novas áreas comerciais.

Dentro do grupo de mexericas, como esperado, quatro híbridos foram resistentes e apenas um (MC x LP 140) mostrou poucos sintomas in vitro após 72 horas de inoculação (média de $0,3 \%$ ). (Tabela 2). Já no grupo de híbridos com frutos tipo tangerina seis híbridos (55\%) foram resistentes (TC x LP 48, TC x LV15, TM x LP 203i; TM x TP 3, 9 e 11), ou seja, não apresentaram sintomas em folhas destacadas e em plantas (Figura 2) e, portanto, podem se constituir em bons materiais visando o uso de resistência varietal como controle da MMA no campo.

No grupo de híbridos classificados como laranjas, dos 45 avaliados, 21 foram assintomáticos (47\% do total avaliado) tanto em folhas destacadas como em plantas (Figura 3). Foram eles: TM x LP 13, 14, 16,
$88,107,110,163,170,200,202,279,324$ e 326; TM x LV 117A, TO x LP 25 e TC x LP 5, 10, 47, 66, 69 e 88. Pelo menos quatro outros híbridos exibiram poucos sintomas quando avaliados em folhas destacadas (TM $\mathrm{x}$ LP 97, 105, 188 e TM x LV 104A) e, portanto, podem ser resistentes no campo. As laranjas representam mais de $80 \%$ dos pomares no estado de São Paulo, ocupando extensas áreas de plantio, cuja produção é destinada essencialmente a indústria de suco. A diversificação de variedades de laranjas é amplamente desejável na citricultura, sendo imprescindível que novas variedades plantadas sejam resistentes à doença para viabilidade econômica da cultura. Apesar de serem fenotipicamente semelhantes às laranjas doces, estes materiais são de origem híbrida e, portanto, alguns indivíduos herdaram a suscetibilidade do genitor Murcott. Apesar de 17 híbridos terem herdado a suscetibilidade a A. alternata do tangor Murcott, um número expressivo de novos genótipos, 21 híbridos, foi resistente, podendo ser de grande interesse econômico para diversificação dos pomares de laranja. Os híbridos avaliados neste trabalho estão sendo validados como novas variedades em ensaios regionais no estado de São Paulo. 


\section{AGRADECIMENTOS}

Os autores agradecem ao CNPq (Processo no 480426/2013-9) e Fapesp (Processos no 2011/21559-0 e 2011/218605-0) pelo auxílio financeiro e ao CNPq pelas bolsas de produtividade em pesquisa de M.B, F.A.A e M.C.Y.

\section{REFERÊNCIAS}

1. Akimitsu, K.; Peever, T.L.; Timmer, L.W. Molecular, ecological and evolutionary approaches to undertanding Alternaria diseases of citrus. Molecular Plant Pathology, Sheffield, v.4, p.435-436, 2003.

2. Azevedo, F.A.D.; Martelli, I.B.; Polydoro, D.A.; Pacheco, C.D.A.; Schinor, E.H.; Bastianel, M. Positive relationship between citrus leaf miner and alternaria brown spot. Ciência Rural, Santa Maria, v.45, n.7, p.1160-1163, 2015.

3. Azevedo, F.A.; Polydoro, D.A.; Bastianel, M.; Kupper, K.C.; Stuart, R.M.; Costa, F.P.; Pio, R.M. Resposta de diferentes genótipos de tangerinas e seus híbridos à inoculação in vitro e in vivo de Alternaria alternata. Revista Brasileira de Fruticultura, Jaboticabal, v.32, p.1-10, 2010.

4. Bastianel, M.; CristofaniYaly, M.; Oliveira, A.C.; FreitasAstúa, J.; Garcia, A.A.F.; Resende, M.D.V.; Rodrigues, V.; Machado, M.A. Quantitative trait loci analysis of citrus leprosis resistance in an interspecific backcross family of (Citrus reticulata Blanco $\times$ C. Sinensis L. Osbeck $) \times C$. Sinensis L. Osb. Euphytica, Berlim, v.169, p.101111, 2009.

5. Bastianel, M.; Simonetti, L.M.; Schinor, E.H.; Giorgi Neto, R.O.; De Negri, J.D.; Gomes, D.N.; Azevedo, F.A. Avaliação do banco de germoplasma de mexericas com relação às características físico-químicas e suscetibilidade à mancha marrom de alternária. Bragantia, Campinas, v.73, p.23-31, 2014.

6. Bella, P.; Guarino, C.; La Rosa, R.; Catara, A. Severe infections of Alternaria spp on a mandarin hybrid. Journal of Plant Pathology, Bari, v.83. p.231, 2001.

7. Canihos, Y.; Peever, T.L., Timmer, L.W. Temperature, leaf wetness, and isolate effects on infection of Minneola tangelo leaves by Alternaria spp. Plant Disease, Iwoa, v.83, p.429-433, 1999.

8. Chutia, M.; Bhuyan, P.D.; Pathak, M.G.; Sarma, T.C.; Boruah, P. Antifungal activity and chemical composition of Citrus reticulata Blanco essential oil against phytopathogens from North East India. Food Science and Technology, Zurich, v.42: p.777-780. 2009.

9. Cristofani, M.; Novelli, V.M.; Perin, M.S.; Oliveira, A.C.; Oliveira, R.P.; Bastianel, M.; Machado, M.A. Programa de melhoramento de citros via hibridação controlada no Centro APTA Citros Sylvio Moreira/IAC no período de 1997 a 2005. Laranja, Cordeirópolis, v.26, n.1, p.121-134, 2005.

10. Cuenca, J.; Aleza, P.; Vicent, A.; Brunel, D.; Ollitrault, P.; Navarro, L. Genetically based location from triploid populations and gene ontology of a 3-3-Mb genome region linked to alternaria brown spot resistance in Citrus reveal clusters of resistance genes. PLoS One, v.8, n.10, p.e76755, 2013. DOI: 10.1371/journal.pone.0076755.

11. Dalkilic, Z.; Timmer, L.W.; Gmitter, F.G. Linkage of an Alternaria disease resistance gene in mandarin hybrids with RAPD fragments. Journal of American Society for Horticultural Science, Alexandria, v.130, n.2, p.191-195, 2005.

12. Elena, K. Alternaria Brown Spot of Minneola in Greece: evaluation of Citrus Species Susceptibility. European Journal of Plant Pathology, Dordrecht, v.115, n.2, p.259-262, 2006

13. Food And Agriculture Organization: FAOESTAT. Database results. 2014. Disponível em <http:// faostat3.fao.org/browse/Q/QC/E > : Acesso em:01 de agosto de 2016.

14. Ferreira, D.F. Sisvar: a computer statistical analysis system. Ciência e Agrotecnologia, Lavras, v.35, n.6, p. 1039-1042, 2011.

15. Gardner, J.M.; Kono, Y.; Chandler, J.L. Biossay and host-selectivity of Alternaria citri toxins affecting rough lemon and mandarins. Physiological and Molecular Plant Pathology, London, v.29, p. 93-304, 1986.

16. Gulsen, O.; Uzun, A.; Canan, I.; Seday, U.; Canihos, E. A new citrus linkage map based on SRAP, SSR, ISSR, POGP, RGA and RAPD markers. Euphytica, Berlim, v.173, n.2, p.265-277, 2010.

17. INSTITUTO BRASILEIRO DE GEOGRAFIA E ESTATÍSTICA. Produção agrícola municipal. Rio de Janeiro, 2016. Disponível em: < http://www.ibge. gov.br/home/estatistica/economia/pam>. Acesso em 01 de agosto de 2016.

18. Kakvan, N.; Zamanizade, H.; Morid, H.B.; Hajmansor, S.; Taeri, H. Evaluation of Citrus Cultivars Resistance to Alternaria alternata, the Causal Agent of Brown Spot Disease, Using RAPD-PCR. Journal of Research in Agricultural Science, Isfahan, v.8, n.1, p.69-76, 2012.

19. Kohmoto, K.; Akimitsu, K.; Otani, H. Correlation of resistance and susceptibility of citrus to Alternaria alternata with sensitivity to host-specific toxins. Phytopathology, Saint Paul, v.81, p.719-722, 1991.

20. Kohmoto, K.; Ito, H.Y.; Shimomura, N.; Kondoh, Y.; Otani, H.; Kodama, M.; Nishimura, S.; Nakatsuka, S. Isolation and biological activities of two host-specific toxins from the tangerine pathotype of Alternaria alternata. Phytopathology, Saint Paul, v.83, p.495-502, 1993.

21. Martelli, I.B. Manejo de mancha marrom de alternaria em citros: poda de limpeza e correlação com lagarta minadora. 2011. 41f. Dissertação (Mestrado em Agricultura Tropical e Subtropical) - Instituto Agronômico de Campinas, Campinas.

22. Oliveira, A.C.; Bastianel, M.; Cristofani-Yaly, M.; Amaral, A.M.; Machado, M. A. Development of genetic map of citrus varieties Murcott tangor and Pera sweet orange by using fluorescent AFLP markers. Journal of Applied Genetics, Poland, v.48, p.219-231, 2007

23. Pacheco, C.A.; Martelli, I.B.; Polydoro, D.A.; Schinor, E.H.; Pio, R.M.; Kupper, K.C., Azevedo, F.A. Resistance and susceptibility of mandarins and their hybrids to Alternaria alternata. Scientia Agricola, Piracicaba, v.69, n.6, p.386-392, 2012.

24. Peever, T.L.; Canilhos, Y.; Olsen, L.; Ibáñez, A.; Liu, Y.C.; Timmer, L.W. Population genetic structure and host specificity of Alternaria spp causing brown spot of Minneola tangelo and rough lemon in Florida. Phytopathology, Saint Paul, v.89, p.851-860, 1999.

25. Peever, T.L.; Olsen, L.; Ibáñez, A.; Timmer, L.W. Genetic differentiation and host specificity among populations of Alternaria spp. causing brown spot of grapefruit and tangerine $\mathrm{x}$ grapefruit hybrids in Florida. Phytopathology, Saint Paul, v.90, n.4, p.407-414, 2000.

26. Peres, N.A.R.; Agostini, J.P.; Timmer, L.W. Outbreaks of Alternaria brown spot of citrus in Brazil and Argentina. Plant Disease, Saint Paul, v.87, p.750, 2003.

27. Reis, R.F.; Almeida, T.F.; Stuchi, E.S.; Goes, A. Susceptibility of citrus species to Alternaria alternata, the causal agent of the Alternaria brown spot. Scientia Horticulturae, Wageningen, v.113, p.336-342, 2007.

28. Soleil, Z. Alternaria brown spot on Minneola tangelos in Israel. Plant Pathology, Malden, v.40, p.145-147, 1991

29. Soleil, Z.; Kimchi, M. Susceptibility and resistance of citrus genotypes to Alternaria alternata pv. citri. Journal Phytopathology, Berlin, v.145, p.389-391, 1997.

30. Souza, M.C.; Stuchi, E.S.; Góes, A. Evaluation of tangerine hybrid resistance to Alternaria alternata. Scientia Horticulturae, Amsterdam, v.123, n.1, p.1-138, 2009.

31. Spósito, M.B.; Feichtenberger, E.; Pio, R.M.; Castro, J.L.; Renaud, M. S.A. Ocorrência de mancha marrom de Alternaria em diferentes genótipos de citros nos estados de Minas Gerais, São Paulo e Rio Grande do Sul. Fitopatologia Brasileira, Brasília, DF, v.28, p.231, 2003.

32. Stuart, R.M.; Bastianel, M.; Azevedo, F.A.; Machado, M.A. Alternaria Brown Spot. Laranja, Cordeirópolis, v.30, n.1, p.29-44, 2009

33. Swart, S.H.; Wingfield, M.J.; Swart, W.J.; Schutte, G.C. Brown spot of Minneola tangelo and efficacy of fungicidal sprays programmes for disease control in South Africa. Proceedings of the International Society of Citriculture, South Africa, v.1, p.379-384, 1996.

34. Timmer, L.W.; Peever, T.L.; Soleil, Z.; Azuya, K.; Kimitsu, A. Alternaria diseases of citrus-novel pathosystems. Phytopathologia Mediterranea, Firenze, v.42, p.99-112, 2003.

35. Timmer, L.W.; Soleil, Z.; Orozco-Santos, M. Alternaria Brown Spot of mandarines. In: TIMMER, L.H.; GARNSEY, S.M.; GRAHAM, J.H. (Ed.). Compendium of Citrus Diseases. 2.ed. Minnesota: APS Press ST Paul, 2000. v.1, p.19-20.

36. Yang, S.L.; Yu, P.L.; Chung, K.R. The glutathione peroxidase-mediated reactive oxygen species resistance, fungicide sensitivity and cell wall construction in the citrus fungal pathogen Alternaria alternata. Environmental Microbiology, Oxford, v.18, n.3, p.923-935, 2016. 